\title{
Triptolide inhibits cell growth and GRP78 protein expression but induces cell apoptosis in original and radioresistant NPC cells
}

\author{
Chengmin $\mathrm{Li}^{1, *}$, Bin Zhang ${ }^{2, *}$, Wuwu Lv ${ }^{1}$, Chen Lai ${ }^{3}$, Zhikang Chen ${ }^{3}$, Ran Wang ${ }^{3}$, \\ Xueying Long ${ }^{4}$, Xueping Feng ${ }^{1}$ \\ ${ }^{1}$ Institute of Medical Sciences, Xiangya Hospital, Central South University, Changsha, Hunan Province 410008, China \\ ${ }^{2}$ Department of Histology and Embryology, Xiangya School of Medicine, Central South University, Changsha, Hunan Province \\ 410008, China \\ ${ }^{3}$ Department of General Surgery, Xiangya Hospital, Central South University, Changsha, Hunan Province 410008, China \\ ${ }^{4}$ Department of Radiology, Xiangya Hospital, Central South University, Changsha, Hunan Province 410008, China \\ *These authors contributed equally to this work
}

Correspondence to: Xueping Feng, email: fxp1029@aliyun.com

Keywords: nasopharyngeal carcinoma, CNE2, radioresistance, triptolide, GRP78

Received: November 05, 2015

Accepted: June 16, 2016

Published: July 06, 2016

\section{ABSTRACT}

The radioresistance is the key factor to hamper curative effect and survival of nasopharyngeal carcinoma (NPC) patients. Nature triptolide (TPL) has been found to circumvent drug-resistant effect of cancer, but its effect on NPC radioresistance has been rarely studied. In the present study, the $10 \mathrm{~Gy}$-resistant CNE2 subclones (CNE2-SR) were used as a NPC radioresistant model. The $\mathrm{IC}_{50}$ of TPL in CNE2 and CNE2-SR cells was measured by MTT assay, cell cycle was analyzed by flow cytometry, and protein expression was examined by western blot. Our data showed that TPL treatment decreased the percentage of viable cells, and IC50 value in CNE2 and CNE2$S R$ cells was $23.6 \pm 1.41 \mathrm{nmol} / L$ and $31.2 \pm 1.16 \mathrm{nmol} / \mathrm{L}$, respectively. Six Gy was a moderate dosage of X-ray for CNE2, and $25 \mathrm{nM}$ TPL was close to IC50 value of CNE2 and CNE2-SR. Six Gy X-ray and/or 25 nM TPL significantly inhibited tumor growth in nude mice. Furthermore, 6 Gy X-ray and/or 25 nM TPL significantly inhibited cell growth and induced cell apoptosis and M/G2 phase arrest in CNE2 and CNE2-SR cells. Moreover, TPL treatment significantly inhibited the expression of GRP78 protein in CNE2 and CNE2-SR cells. These results suggest that TPL may serve as a potential radiosensitizer agent for NPC treatment.

\section{INTRODUCTION}

Increasing incidence and mortality rate of cancers urge researchers to make great effort on searching for novel anti-cancer drugs or therapies. Many active compounds from natural herbs, such as Taxol, have been demonstrated to have antitumor activity and widely used in cancer therapy. Triptolide (TPL, molecular formula: $\mathrm{C}_{20} \mathrm{H}_{24} \mathrm{O}_{6}$ ) active components extracted from Chinese herb Tripterygium wilfordii Hook $\mathrm{F}$ (known as Lei Gong Teng or Thunder of God Vine) were usually used for rheumatoid arthritis therapy, but they also showed antitumor activity through inducing tumor cell apoptosis [1-3]. It has been found that TPL induces cell apoptosis via inhibiting HSP70 in pancreatic cancer cells [4]. Moreover, TPL treatment circumvents drug-resistant effect and enhances the anti-tumor effect of 5-fluorouracil in $\mathrm{KB}$ cells [5].

Nasopharyngeal carcinoma (NPC) is a kind of rare epithelial cancer, but it is one of the most prevalent malignancies in southern Chinese populations. However, the clinical outcome and prognosis of NPC remain unsatisfactory. Radioresistance is the biggest obstacle to achieve long-term survival. So it is urgent to screen some novel and effective drugs to treat radioresistant NPC. GRP78 is an ER chaperone protein and major regulator of the unfolded protein response (UPR) [6]. The response of GRP78 to drug-induced ER stress has been well established [6]. GRP78 may be an important biomarker protein for drug resistance.

The efficacy of TPL in NPC therapy and its molecular mechanisms have been poorly studied. In this study, we first examined the $\mathrm{IC}_{50}$ value of TPL in 
NPC CNE2 and CNE2-SR cells by MTT assay. Then, we further investigated that the effects of TPL on cell proliferation, cell cycle and the expression of GRP78 in both cells.

\section{RESULTS}

\section{The radioresistant CNE2-SR from the irradiated CNE2 cells}

The 10 Gy dose of X-ray radiation resulted in $95 \%$ of cell death in CNE2. After 15 days, the residual cells formed some clones ( $>50$ cells in each clone). The clones were more resistant than the parent CNE2 in vitro (Figure 1C-1D; Figure 3A) and in vivo (Figure 3D-3E). Then the clones were isolated and cultured as a radiationresistant sample, CNE2-SR.

\section{TPL decreases cell viability and inhibits tumor growth}

The viability in CNE2 and CNE2-SR cells was significantly decreased in a concentration-dependent manner after treatment with various doses $(0.05-500 \mathrm{nM})$ of TPL (Figure 2A). Moreover, consistent with MTT assay, the number of viable cells was gradually decreased along with the increasing dose of TPL treatment (Figure 2B). There was no significant difference in the number of viable cells treated with various doses of TPL between CNE2 and CNE2-SR $(p>0.01)$ despite their different radiosensitivity (Figure 1A-1E). IC50 value in CNE2 and CNE2-SR cells was $23.6 \pm 1.41 \mathrm{nmol} / \mathrm{L}$ and $31.2 \pm 1.16 \mathrm{nmol} / \mathrm{L}$, respectively. The $25 \mathrm{nM}$ TPL was close to IC50 value of CNE2 and CNE2$\mathrm{SR}$, and $25 \mathrm{nM}$ TPL significantly inhibited tumor growth of CNE2 and CNE2-SR in vivo (Figure 2D and Figure 2E).

A

B
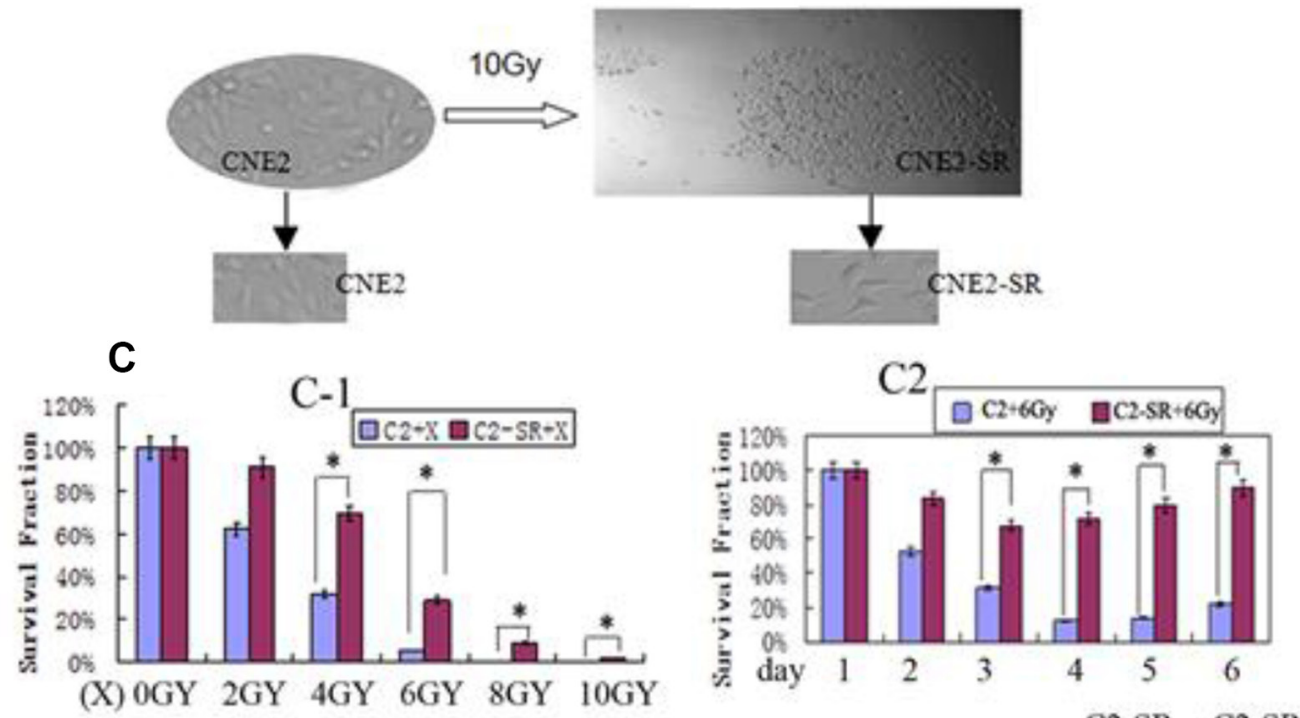

D
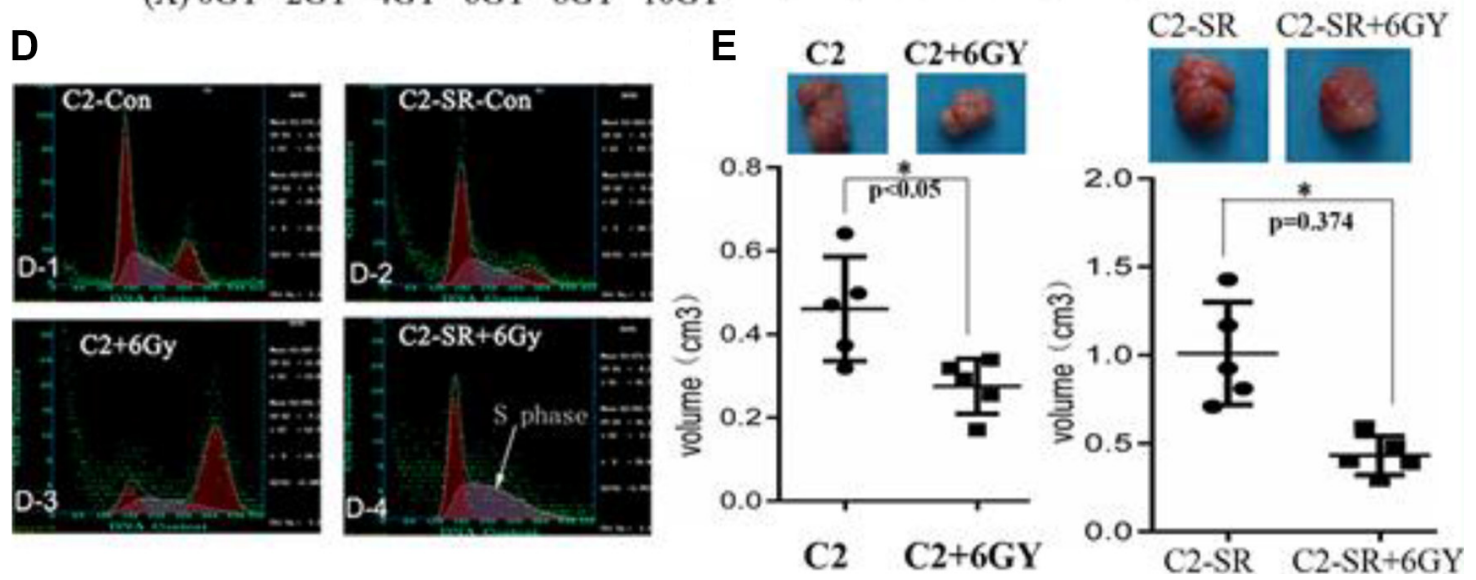

Figure 1: The radioresistant CNE2-SR subclones. (A) NPC CNE2 cell line (CNE2); (B) CNE2-SR subclones (CNE2-SR) derived from the survival CNE2 cells by a large dosage of $10 \mathrm{~Gy}$. (C-1) The survival fractions of CNE2-SR (C2-SR+X) were higher compared with CNE2 (C2 + X) after various X-ray (2-10 Gy); (C-2)The survival fractions of CNE2-SR (C2-SR + 6Gy) were higher compared with CNE2 (C2 + 6Gy) at various days (1-6 day) by 6 Gy. (D) Cell cycle analysis of CNE2 (C2+6Gy) and CNE2-SR (C2-SR + 6Gy) after 6 Gy $\mathrm{X}$-ray for $48 \mathrm{~h}$. (E) Measurement of tumor growth for CNE2 (C2 + 6Gy) and CNE2-SR (C2-SR + 6Gy) in nude mice (every group, $n=5)$ after treatment of 6 Gy. 


\section{Cell growth analysis in response to TPL and radiation}

Six Gy was a moderate dosage of X-ray for CNE2, and $25 \mathrm{nM}$ TPL was close to IC50 value in CNE2 and CNE2-SR. The proliferation of CNE2 and CNE2-SR cells was monitored at various time intervals after treatment with 6 Gy X-ray and/or $25 \mathrm{nM}$ TPL. As shown in the Figure 3, both CNE2 and CNE2-SR cells were sensitive to $25 \mathrm{nM}$ TPL treatments (Figure 3B), but CNE2-SR cells were more resistant to $6 \mathrm{~Gy} \mathrm{X}$-ray compared with $\mathrm{CNE} 2$

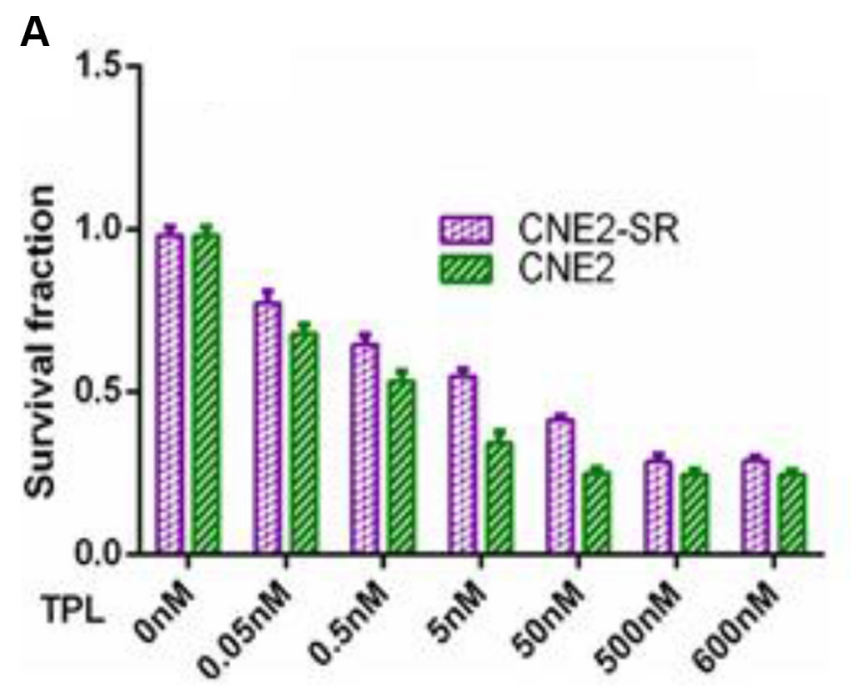

cells (Figure 3A). Moreover, the combined treatments of 6 Gy X-ray and $25 \mathrm{nM}$ TPL completely inhibited cell proliferation in both cell lines in vitro (Figure $3 \mathrm{C}$ ) and in vivo (Figure 3D-3E).

\section{TPL treatment enhances the anti-tumor effect of $\mathrm{X}$-ray in vivo}

To confirm the radiosensitizer effect of TPL to CNE2-SR cells, TPL was tested with radiationresistant CNE2-SR in vivo. The radiosensitizer
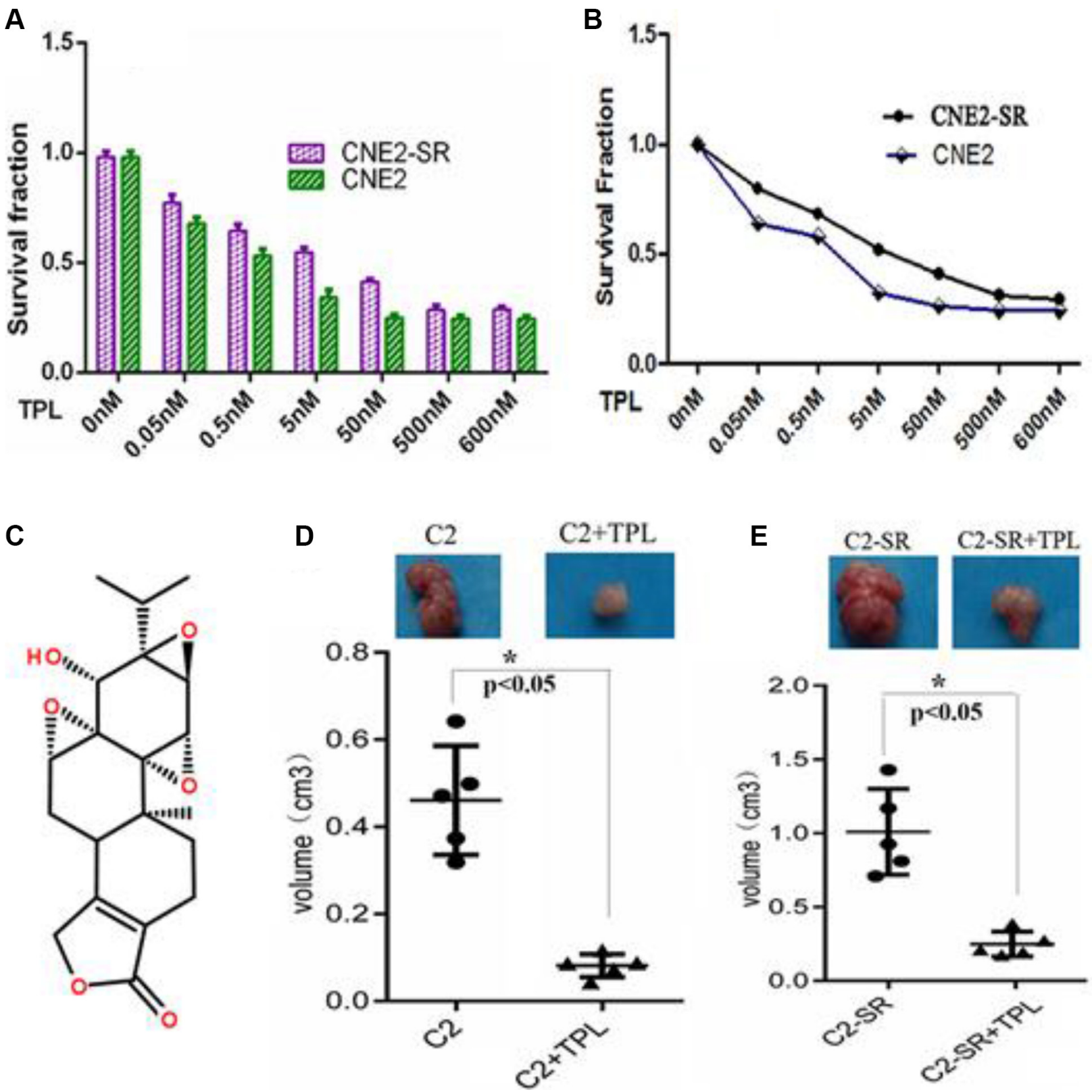

Figure 2: TPL inhibits cell proliferation in the CNE2-SR and CNE2 cells. (A) Measurement of cell viability in CNE2 and CNE2-SR cells after treatment of various concentrations of TPL (0.05-500 nM) using MTT assay. The IC50 value of TPL in CNE2 and CNE2-SR cells was calculated. (B) Measurement of cell growth in CNE2 and CNE2-SR cells after treatment of various concentrations of TPL $(0.05-500 \mathrm{nM})$ by counting cell number. The cell number in all treated groups was compared to that of untreated cells, and the survival of untreated cells was set as 1. (C) The structure of TPL molecule; (D and E) Measurement of tumor growth for CNE2 (C2) and CNE2-SR $(\mathrm{C} 2-\mathrm{SR})$ in nude mice (every group, $n=5$ ) after treatment of $25 \mathrm{nM}$ TPL. 
effects of TPL on NPC radioresistance were tested in nude mice. The combined treatments of $6 \mathrm{~Gy} \mathrm{X}$-ray or/and $25 \mathrm{nM}$ TPL significantly inhibited tumor growth of the radioresistant CNE2-SR in nude mice
(Figure 3D and 3E). TPL treatment enhanced the antitumor effect of X-ray, and circumvented the resistant effect of X-ray in the nude mice transplanted with CNE2-SR cells (Figure 3E).

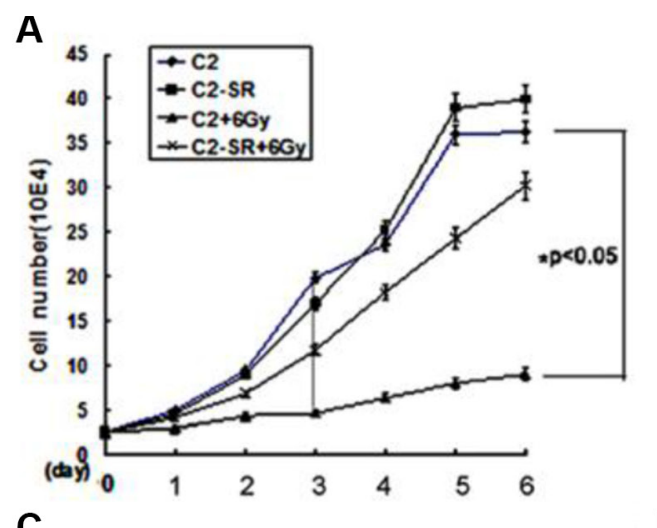

B

C
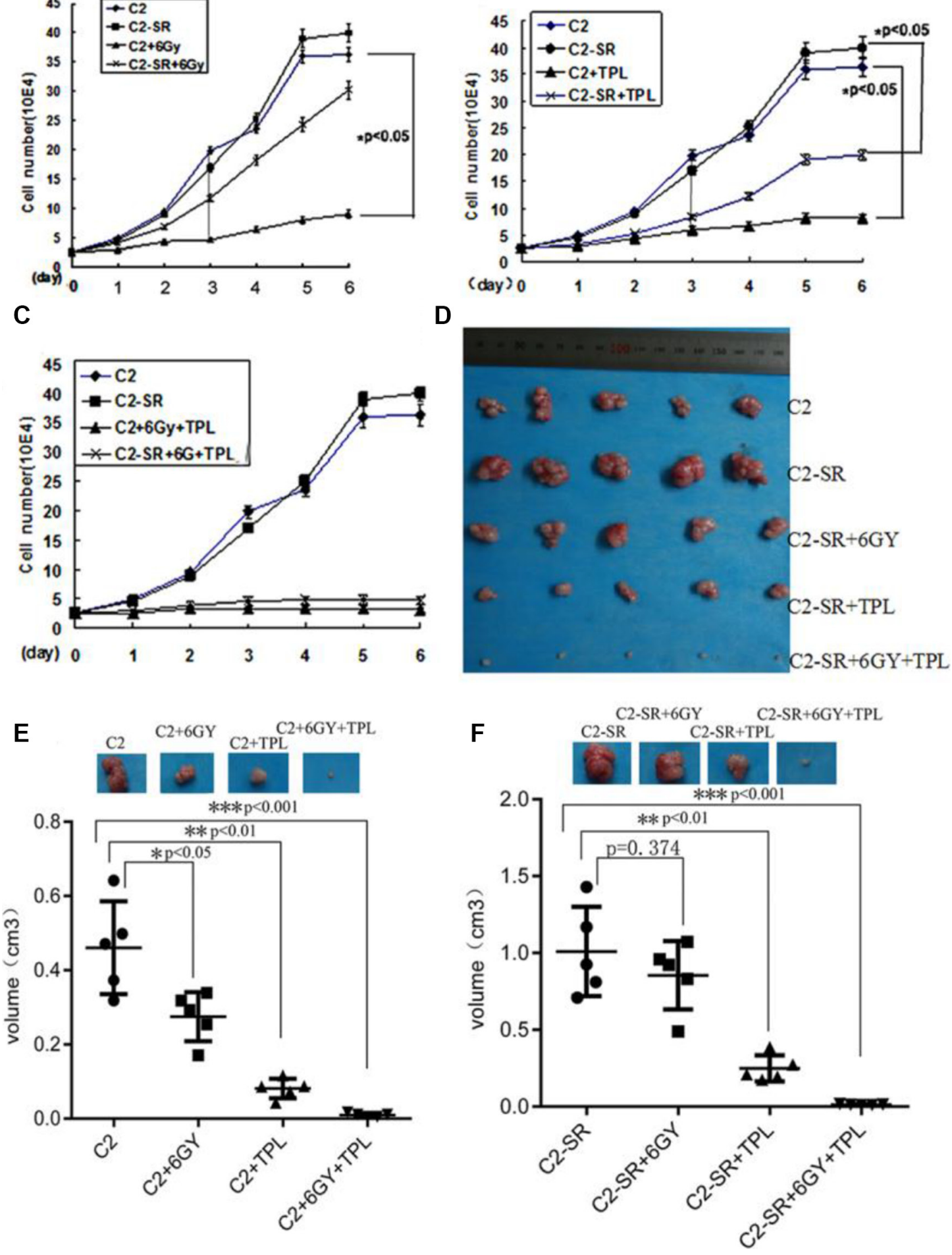

Figure 3: Effect of TPL and radiation on cell growth at different time points. (A) Effect of 6 Gy X-ray (6 Gy) on cell growth in CNE2 (C2) and CNE2-SR (C2-SR) cells at different time points. (B) Effect of $25 \mathrm{nM}$ TPL on cell growth in CNE2 and CNE-SR cells at different time points. (C) Effect of the combined treatments of 6 Gy X-ray and $25 \mathrm{nM}$ TPL on cell growth in CNE2 and CNE2-SR cells at different time points. Cell growth was assessed by counting cell number. (D) The representative images of tumor. (E) and (F) the analysis of tumor growth for CNE2 (C2) and CNE2-SR (C2-SR) after treatment of X-ray and/or $25 \mathrm{nM}$ TPL in nude mice (every group, $n=5$ ). 


\section{TPL enhances the radiosensitivity of cells and changes cell cycle transition}

We examined the effect of combined treatments of 6 Gy X-ray and $25 \mathrm{nM}$ TPL on cell apoptosis and cell cycle analysis by the staining of Hoechst 33258 and Annexin V-FITC/propidium iodide (PI). As shown in the Figure 4, the combined treatments of 6 Gy X-ray and $25 \mathrm{nM}$ TPL significantly induced cell apoptosis in CNE2 and CNE2-SR cells (Figure 4A-4C). We further found that the majority of untreated CNE2 and CNE2-SR cells were in G0/G1 phase(Figure $4 \mathrm{D}_{1-2}$ and Figure $5 \mathrm{~A}$ ). The treatments of $25 \mathrm{nM}$ TPL or/and 6 Gy significantly promoted cell cycle transition from $\mathrm{G} 0 / \mathrm{G} 1$ to $\mathrm{G} 2 / \mathrm{M}$ phase (Figure $4 \mathrm{D}_{3,5,7}$; Figure 5A) in CNE2 cells, but this effect was not observed in CNE2-SR cells treated with 6Gy X-ray (Figure 4D;
Figure 5A). However, the treatment of 6 Gy X-ray in CNE2-SR significantly promoted the transition from G2/M to S phase (Figure 4D; ; Figure 5A). Moreover, the combined treatments of 6 Gy X-ray and $25 \mathrm{nM}$ TPL in CNE2-SR cells further promoted cell cycle transition from G0/G1 to $\mathrm{G} 2 / \mathrm{M}$ phase again (Figure $4 \mathrm{D}_{8}$ ).

\section{TPL inhibits GRP78 protein expression and colony formation}

Since GRP78 is one of important biomarkers for drug-induced ER stress [6], here we examined the expression of GRP78 protein. As shown in the Figure 5, the expression of GRP78 protein in CNE2-SR cells was significantly higher than that in CNE2 cells, while $25 \mathrm{nM}$ TPL but not 6 Gy X-ray significantly inhibited the
A

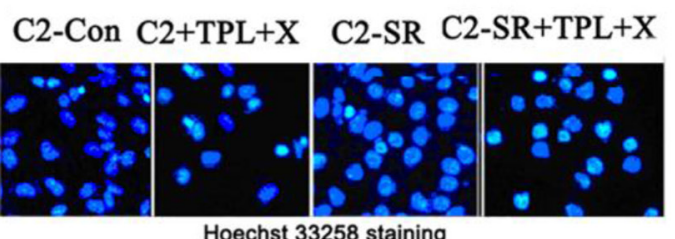

C

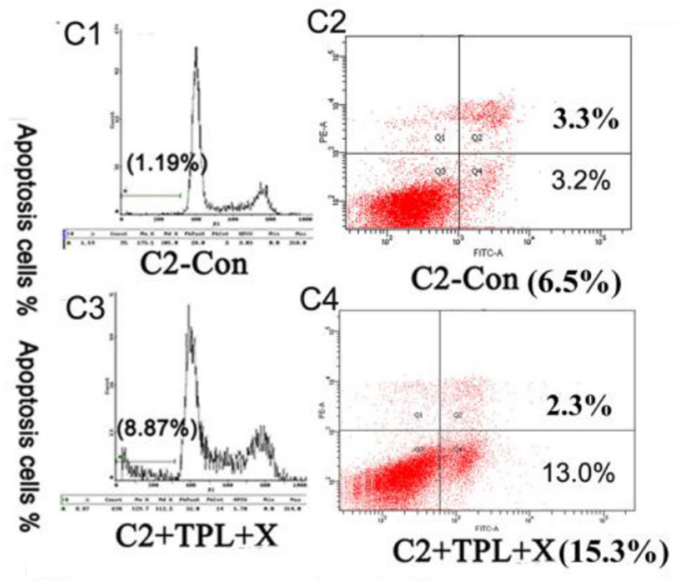

B
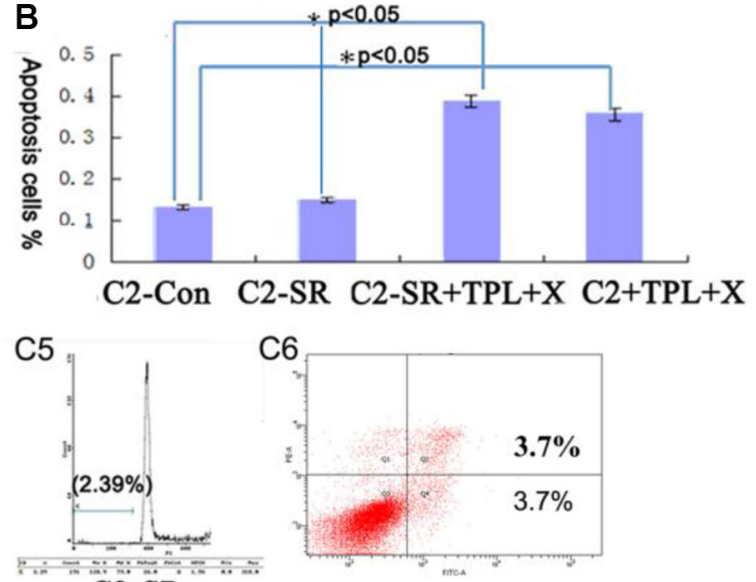

$\mathrm{C} 2$-SR
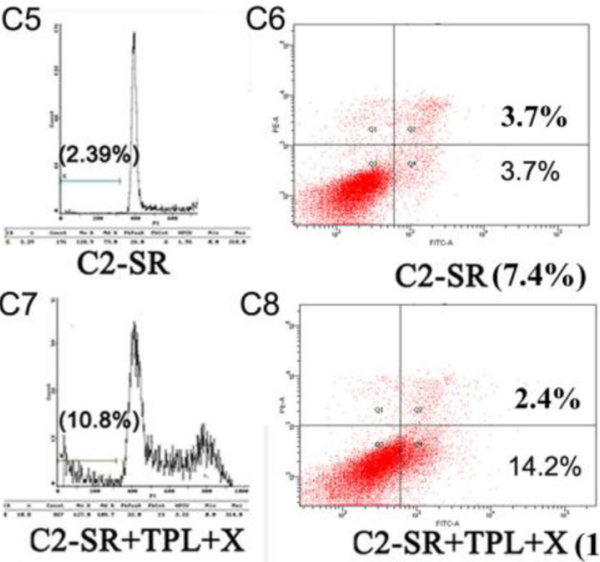

$\mathrm{C} 2-\mathrm{SR}+\mathrm{TPL}+\mathrm{X}(16.6 \%)$
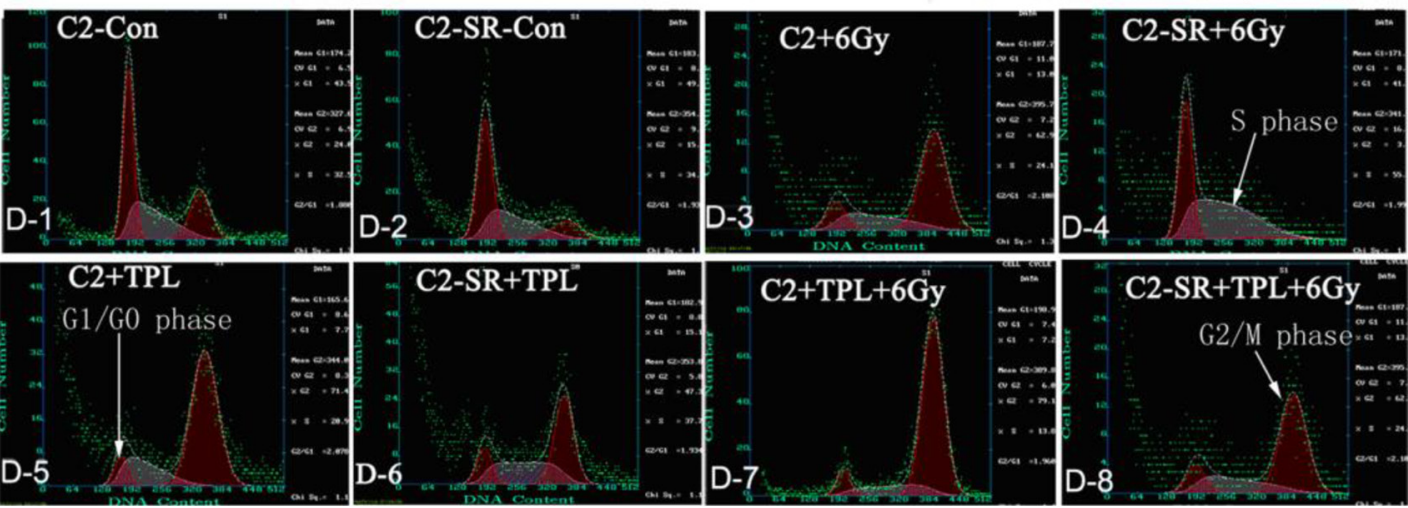

Figure 4: TPL induces cell apoptosis and M/G2 phase arrest. (A) Assay of cell apoptosis by Hoechst 33258. Both CNE2 (C2) and CNE2-SR (C2-SR) cells were cultured in 6-well culture plates and treated with 6 Gy X-ray and $25 \mathrm{nM}$ TPL for $48 \mathrm{~h}$. (B). Statistical analysis cell apoptosis based on Hoechst 33258 staining from three independent experiments $(n=3)$. The data are presented as mean \pm standard deviation (SD). ${ }^{*} p<0.05$. (C) Measurement of cell apoptosis by flow cytometry after Annexin V-FITC/propidium iodide (PI). (D) Cell cycle analysis of CNE2 and CNE2-SR cells after 6 Gy X-ray and/or $25 \mathrm{nM}$ TPL for $48 \mathrm{~h}$. 
expression of GRP78 protein after individual or combined treatments (Figure 5B and 5C). Interestingly, the level of GRP78 protein was negatively correlated with the proportion of $\mathrm{G} 2 / \mathrm{M}$ phase cells (Figure 5A-5C). Moreover, we examined the colony formation capacity after $25 \mathrm{mM}$ TPL and/or 6 Gy X-ray treatments (Figure 5D and 5E). Both 6 Gy X-ray and $25 \mathrm{nM}$ TPL treatments significantly inhibited colony formation in CNE2 and CNE2-SR cells (Figure 5D and 5E).

\section{DISCUSSION}

The standard combination of radiotherapy and chemotherapy has improved the efficiency in NPC patients, but radioresistance is still the common causes of biggest obstacle in NPC treatment [7-9]. The survival of irradiated NPC cells is the most common cause for the relapse and metastasis of NPC. In the present study, we established radioresistant CNE2-SR subclones from CNE2 cells by 10 Gy X-ray radiation, which were more resistant to $6 \mathrm{~Gy} \mathrm{X}$-ray radiation compared with original CNE2 cells. TPL is a natural drug with anticancer efficacy, and has been used as a good alternative in many cancer treatments. Early in 1972, Kupchan et al. first reported the antileukemic effect of TPL [10]. The combination of TPL and X-ray showed synergistic effects in preclinical animal models [11]. Jacobson et al. [12] found that TPL inhibits pancreatic cancer cell proliferation through reducing the expression of heat shock protein 70 . However, the efficacy of TPL in NPC therapy has not yet been addressed.
Our data showed that TPL decreased the percentage of viable cells in the radioresistant CNE2SR cells. The combination of TPL and X-ray showed synergistic effects and circumvented the resistant effect of X-ray in the nude mice transplanted with CNE2-SR cells. It has been demonstrated that the cells at G2/M phase are most sensitive to radiation, and G2/M phase arrest is one of the major reasons of cell death caused by anti-tumor drugs and radiosensitive reagents [13]. Significant elevation of GRP78 expression in cancer cells is linked to a radioresistant cell type [6-7]. GRP78 is known to induce anti-apoptosis, chemoresistance and radioresistance. GRP78 has been considered as a potential biomarker for therapy-resistance in multiple carcinomas [14-15]. Li et al. found that GRP78 enhances the glutamine metabolism and supports cell survival from glucose deficiency by activating the $\beta$-catenin signaling [14], while GRP78 inhibitor OSU03012/sildenafil could kill brain cancer stem cells [15]. This evidence suggests that the down-regulation of GRP78 may inhibit cell survival. Here we observed that the combined treatments of 6 Gy X-ray and $25 \mathrm{nM}$ TPL could promote cell cycle transition from G0/G1 to G2/M phase in the radioresistant CNE2-SR cells. Moreover, the G2 /M phase arrest and cell apoptosis in CNE2-SR cells accompanied the downregulation of GRP78 protein expression. Hence, we speculate that the elevated GRP78 protein may support cell survival and enhance radioresistance to 6 Gy $\mathrm{X}$-ray radidation in CNE2-SR cells.
A

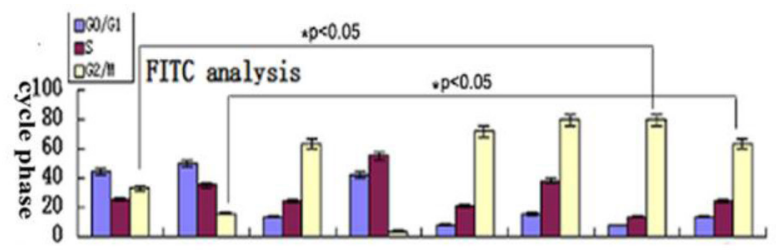

B

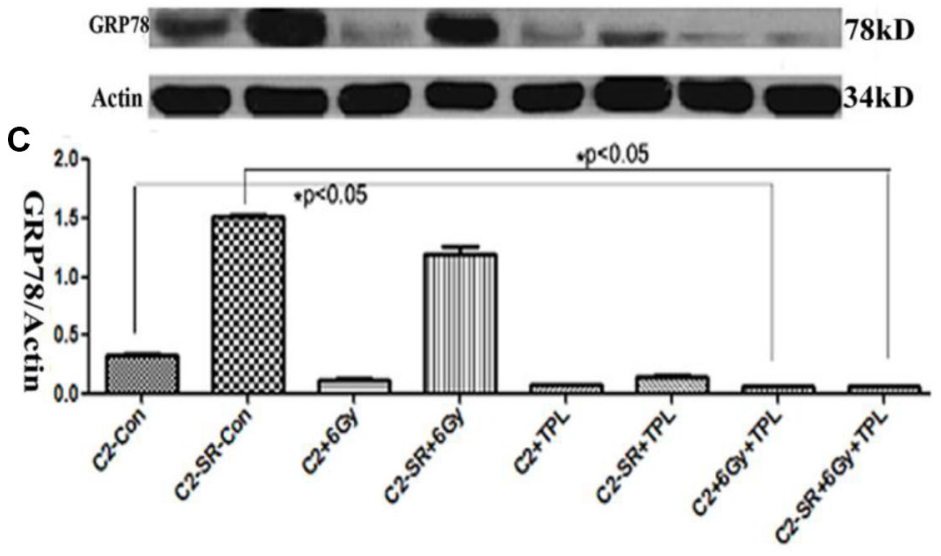

D
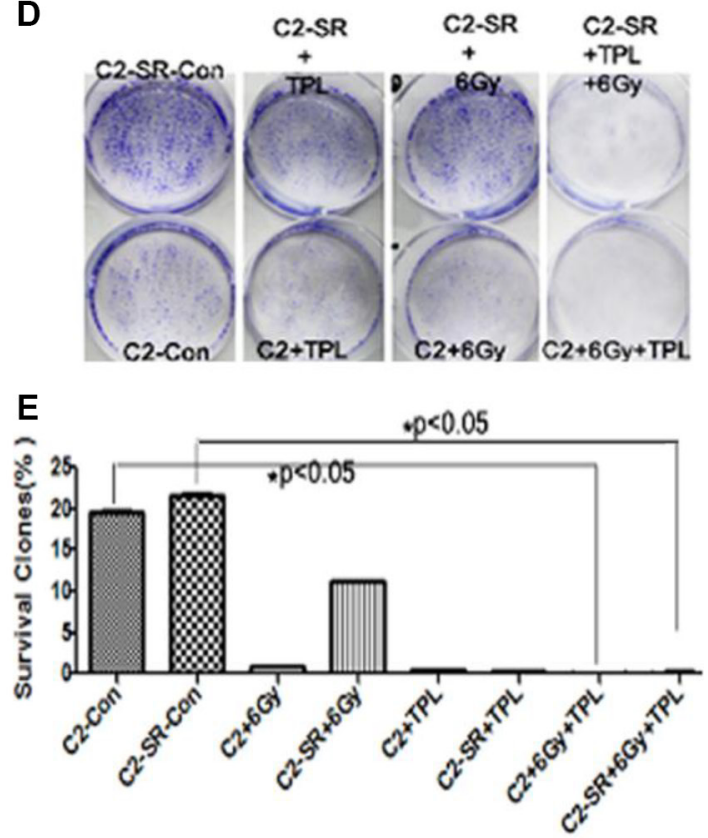

Figure 5: TPL inhibits the expression of GRP78 protein and colony formation capacity. (A) Cell cycle analysis of CNE2 and CNE2-SR cells after 6 Gy X-ray and/or $25 \mathrm{nM}$ TPL. (B) Effect of 6 Gy X-ray and/or $25 \mathrm{nM}$ TPL on GRP78 expression in CNE2 (C2) and CNE2-SR (C2-SR) cells and (C) Statistical analysis of GRP78 protein expression from three independent experiments $(n=3)$. The data are presented as mean $\pm \mathrm{SD},{ }^{*} P<0.05$. (D) Effect of 6 Gy X-ray and/or $25 \mathrm{nM}$ TPL on colony assay in CNE2 (C2) and CNE2-SR (C2-SR) cells. (E) Statistical analysis of colony formation in CNE2 and CNE2-SR cells. The data are presented as mean \pm SD. ${ }^{*} p<0.05$. 
TPL has been found to sensitize cancer cells to apoptosis [16-18]. Moreover, a recent study reported that the expression of GRP78 in pancreatic cancer cell lines is downregulated by TPL, leading to cell apoptosis and autophagy [19]. TPL may provide new insight and knowledge for future studies in NPC radioresistant field. Radioresistance is mostly associated with numerous molecular aberrations that characterize glioblastoma, such as enhanced DNA damage repair (DDR) and activation of pro-survival signaling pathways [21]. GRP78 is a critical pro-survival chaperone involved in ER stress linked to the changes in ROS balance secondary to irradiation [22]. Consistently, our results suggest that TPL may trigger apoptosis and induce G2/M phase arrest via inhibiting GRP78. Thus, TPL may serve as a potential chemotherapeutic agent and new radiosensitizer for NPC treatment.

\section{MATERIALS AND METHODS}

\section{The survival subclones of CNE2 cells to irradiation}

CNE2 cells were seeded at a density of $1.0 \times 10^{5}$ cells per $6 \mathrm{~cm}$ plate and cultured in RPMI-1640 medium (Gibco BRL) containing 10\% heat-inactivated fetal bovine serum (FBS, HyClone) and $1 \%$ antibiotics at $37^{\circ} \mathrm{C}$ in a humidified $5 \% \mathrm{CO}_{2}$ incubator. After $24 \mathrm{~h}$ culture, the cells were exposed to sublethal 10 Gy dose (300 cGy/min) of X-ray at room temperature using a linear accelerator (2100EX, Varian). Fifteen days after treatment, the residual CNE2 cells were cultured and named for CNE2SR (CNE2 Survival-Residual subclones). CNE2 cells irradiated with sham were used as a control.

\section{Cell viability analysis by MTT assay}

To evaluate the anticancer effect of TPL on NPC cell lines, IC50 of TPL in CNE2 and CNE2-SR cells was examined by 3-(4, 5-dimethylthiazol-2-yl)-2, 5-diphenyltetrazolium bromide (MTT) assay. Cells were cultured at $5.0 \times 10^{3} /$ well in 96 -well plates for $24 \mathrm{~h}$, then treated with $0.01 \mathrm{mM}$ PBS (control samples) and various doses (0.05 nM, $0.50 \mathrm{nM}, 5 \mathrm{nM}, 50 \mathrm{nM}, 500 \mathrm{nM}$ and $600 \mathrm{nM}$, diluted in culture medium.) of TPL for 48 h. $20 \mu \mathrm{l}$ of MTT dye (3 g/L in PBS; Sigma-Aldrich) were added to each well and incubated for $4 \mathrm{~h}$. The absorbance of each well was read at $630 \mathrm{~nm}$ on an EL310 Microplate Autoreader (Bio-Tek Instruments). Cell viability was calculated by comparison of the A630 readings to the control absorbance. Three independent experiments were conducted. IC50 value of TPL in CNE2 and CNE2-SR cells was calculated.

\section{Cell growth analysis by cell counting}

CNE2 and CNE2-SR cells were plated at a density of $4 \times 10^{4}$ cells/well in triplicate in a 6-well plate and exposed to $25 \mathrm{nM}$ of TPL and/or 6 Gy of X-ray. Cell growth was monitored by counting cell number at various time intervals. Three independent experiments performed.

\section{Cell apoptosis and cell cycle analysis by flow cytometry}

$2.5 \times 10^{6}$ cells were treated with TPL $(25 \mathrm{nM})$ and/ or X-ray (6 Gy) and harvested after $48 \mathrm{~h}$ treatment. Cell pellets were fixed with ice-cold $70 \%$ ethanol in PBS at $-20^{\circ} \mathrm{C}$ for $1 \mathrm{~h}$ and then centrifuged at 1,500 rpm for $5 \mathrm{~min}$. The pellet was incubated with $0.5 \%$ Triton X-100 (Sigma) and $0.05 \%$ RNase (Sigma) in $1 \mathrm{~mL}$ PBS at $37^{\circ} \mathrm{C}$ for $30 \mathrm{~min}$ and then centrifuged at $1,500 \mathrm{rpm}$ for $5 \mathrm{~min}$. For cell cycle analysis, cell pellets were resuspended in $1 \mathrm{~mL}$ PBS containing $40 \mu \mathrm{g} / \mathrm{mL}$ propidium iodide (PI, Sigma) and incubated for $30 \mathrm{~min}$ in dark at room temperature. For cell apoptosis, cells were washed with $1 \times \operatorname{PBS}\left(4^{\circ} \mathrm{C}\right)$, incubated with $300 \mu \mathrm{L} 1 \times$ Binding Buffer containing $5 \mu \mathrm{L}$ Annexin V-FITC and $5 \mu \mathrm{L}$ with PI for $30 \mathrm{~min}$ in dark at room temperature. Samples were immediately analyzed by a FAC-Scan flow cytometry (Becton-Dickinson). The distribution of cell cycle was analyzed using Flow Jo, CellQuest Pro and the ModiFit software. Three independent experiments were performed.

\section{Hoechst 33258 staining of cells}

Cells were grown on coverslips in 6-well plate. The morphology and apoptosis of cells were examined by staining with cell-permeable DNA dye Hoechst 33258 (Sigma). Briefly, cells were fixed with ice-cold 70\% ethanol in PBS for $30 \mathrm{~min}$ after exposure to TPL (25 nM) and/or X-ray (6 Gy) for $48 \mathrm{~h}$, then stained with $5 \mu \mathrm{g} / \mathrm{mL}$ cell-permeable DNA dye Hoechst 33258 (Sigma) dissolved in Hanks' buffer for $10 \mathrm{~min}$ in the dark. Cells with homogeneously stained nuclei were considered to be viable, whereas the presence of chromatin condensation and/or fragmentation was indicative of apoptosis. To calculate the percentage of apoptotic cells, at least 200 cells in three different microscopic fields were evaluated.

\section{Western blot analysis}

CNE2 and CNE2-SR cells were seeded at a density of $8 \times 10^{4}$ cells/well in a 6 -well plate and cultured in the presence of TPL (25 nM) and/or X-ray (6 Gy) for $48 \mathrm{~h}$. Western blot was carried out as previously described [7]. Briefly, $50 \mu \mathrm{g}$ of cell lysates were separated by $10 \%$ SDSPAGE and transferred onto polyvinylidene difluoride membrane. Blots were blocked with 5\% nonfat milk for $2 \mathrm{~h}$ at room temperature and then incubated with polyclonal goat anti-GRP78 antibody (1: 2,000 dilution, Santa Cruz Biotechnology, Santa Cruz, CA) at $4^{\circ} \mathrm{C}$ overnight. The membranes were washed and incubated with horseradish peroxidase-conjugated secondary antibody (1: 2000, 
Santa Cruz Biotechnology). As a loading control, $\beta$-actin was detected simultaneously using monoclonal mouse anti- $\beta$-actin antibody (1: 3,000 dilution, Sigma). Visualization was performed with an Amersham-enhanced chemiluminescence system. The intensity of bands was quantified by software. All experiments were repeated three times.

\section{Colony formation assay}

Radioresistance of cells was measured by clonogenic survival assay following exposure to irradiation. The clonogenic survival assay was carried out as described previously [7, 20]. Briefly, cells were plated in six-well culture plates and were exposed to 6 Gy X-ray. After irradiation, the cells were cultured for 15 days and the number of surviving colonies (defined as a colony with $>50$ cells) was counted. After staining with crystal violet, cell colonies were counted under a microscope. The survival fraction was calculated based on the formula: number of colonies counted/(number of cells plated $x$ plating efficiency). Three independent experiments were performed.

\section{The radiosensitizer effects of TPL in Xenograft mouse model}

To evaluate the pharmacodynamics of TPL, we compared the antitumor efficiency of TPL or/and X-ray in xenograft mouse model of CNE2 and CNE2-SR in vivo. Three week-old nude mice were subcutaneously inoculated with $1 \times 10^{7} \mathrm{CNE} 2 / \mathrm{CNE} 2-\mathrm{SR}$ cells diluted with 1640 medium. The tumors were treated in the presence of TPL (25 nM) and/or X-ray (6 Gy) after tumor formation. The body weight and tumor volume were monitored and calculated every 3 days for 30 days. The tumor volumes were calculated by the equation $\mathrm{V}\left(\mathrm{mm}^{3}\right)=\mathrm{a} \times \mathrm{b}^{2} / 2$, where " $a$ " is the largest diameter and " $b$ " is the perpendicular diameter.

\section{Statistical analysis}

Statistical analyses were performed using SPSS 13.0 and Graphpad Prism 5.0. The difference in GRP78 expression between CNE2 and CNE2-SR cells was analyzed using $T$ test. $P<0.05$ was considered statistically significant.

\section{ACKNOWLEDGMENTS AND FUNDING}

This study was supported by the grants from National Natural Science Foundation of China (81372905 to Xueping Feng; 81301997 to Bin Zhang) and Hunan Provincial Natural Science Foundation of China (2015JJ4075 to Xueping Feng ).

\section{CONFLICTS OF INTEREST}

The authors declare no competing financial interests.

\section{REFERENCES}

1. Zhong YY, Chen HP, Tan BZ, Yu HH, Huang XS. Triptolide avoids cisplatin resistance and induces apoptosis via the reactive oxygen species/nuclear factor- $\kappa \mathrm{B}$ pathway in SKOV3PT platinum-resistant human ovarian cancer cells. Oncol Lett. 2013; 6:1084-1092.

2. Li M, Zhang X, Zhou WJ, Chen YH, Liu H, Liu L, Yang CM, Qan WB. Hsp90 inhibitor BIIB021 enhances triptolideinduced apoptosis of human T-cell acute lymphoblastic leukemia cells in vitro mainly by disrupting p53-MDM2 balance. Acta Pharmacol Sin. 2013; 34:1545-1553.

3. Meng C, Zhu H, Song H, Wang Z, Huang G, Li D, Ma Z, Ma J, Qin Q, Sun X, Ma J. Targets and molecular mechanisms of triptolide in cancer therapy. Chin J Cancer Res. 2014; 26:622-626.

4. MacKenzie TN, Mujumdar N, Banerjee S, Sangwan V, Sarver A, Vickers S, Subramanian S, Saluja AK. Triptolide induces the expression of miR-142-3p: a negative regulator of heat shock protein 70 and pancreatic cancer cell proliferation. Mol Cancer Ther. 2013; 12:1266-1275.

5. Chen YW, Lin GJ, Chuang YP, Chia WT, Hueng DY, Lin CK, Nieh S, Sytwu HK. Triptolide circumvents drugresistant effect and enhances 5-fluorouracil antitumor effect on KB cells. Anticancer Drugs. 2010; 21:502-513.

6. Pfaffenbach KT, Pong M, Morgan TE, Wang H, Ott K, Zhou B, Longo VD, Lee AS. GRP78/BiP is a novel downstream target of IGF-1 receptor mediated signaling. J Cell Physiol. 2012; 227:3803-3811.

7. Feng XP, Yi H, Li MY, Li XH, Yi B, Zhang PF, Li C, Peng F, Tang CE, Li JL, Chen ZC, Xiao ZQ. Identification of biomarkers for predicting nasopharyngeal carcinoma response to radiotherapy by proteomics. Cancer Res. 2010; $70: 3450-3562$.

8. Yang S, Chen J, Guo Z, Xu XM, Wang L, Pei XF, Yang J, Underhill CB, Zhang L. Triptolide inhibits the growth and metastasis of solid tumors. Mol Cancer Ther. 2003; 2:65-72.

9. Wei P, Niu M, Pan S, Zhou Y, Shuai C, Wang J, Peng S, Li G. Cancer stem-like cell: a novel target for nasopharyngeal carcinoma therapy. Stem Cell Res Ther. 2014; 5:44.

10. Kupchan SM, Court WA, Dailey RG Jr, Gilmore CJ, Bryan RF. Triptolide and tripdiolide, novel antileukemic diterpenoid triepoxides from Tripterygium wilfordii. J Am Chem Soc. 1972; 94:7194-7195.

11. Yang S, Chen J, Guo Z, Xu XM, Wang L, Pei XF, Yang J, Underhill CB, Zhang L. Triptolide inhibits the growth and metastasis of solid tumors. Mol Cancer Ther. 2003; 2:65-72. 
12. Jacobson BA, Chen EZ, Tang S, Belgum HS, McCauley JA, Evenson KA, Etchison RG, Jay-Dixon J, Patel MR, Raza A, Saluja AK, D'Cunha J, Kratzke RA. Triptolide and its prodrug minnelide suppress $\mathrm{Hsp} 70$ and inhibit in vivo growth in a xenograft model of mesothelioma. Genes Cancer. 2015; 6:144-152. doi: 10.18632/genesandcancer.55.

13. Zhang T, Yu H, Dong G, Cai L, Bai Y. Chamaejasmine arrests cell cycle, induces apoptosis and inhibits nuclear $\mathrm{NF}-\kappa \mathrm{B}$ translocation in the human breast cancer cell line MDA-MB-231. Molecules. 2013; 18:845-858.

14. Li Z, Wang Y, Wu H, Zhang L, Yang P, Li Z. GRP78 enhances the glutamine metabolism to support cell survival from glucose deficiency by modulating the $\beta$-catenin signaling. Oncotarget. 2014; 5:5369-5380. doi: 10.18632/ oncotarget.2105.

15. Booth L, Roberts JL, Cash DR, Tavallai S, Jean S, Fidanza A, Cruz-Luna T, Siembiba P, Cycon KA, Cornelissen CN, Dent P. GRP78/BiP/HSPA5/Dna $\mathrm{K}$ is a universal therapeutic target for human disease. J Cell Physiol. 2015; 230:1661-1676.

16. Lin J, Chen LY, Lin ZX, Zhao ML. The effect of triptolide on apoptosis of glioblastoma multiforme (GBM) cells. J Int Med Res. 2007; 35:637-643.

17. Liu Y, Chen F, Wang S, Guo X, Shi P, Wang W, Xu B. Lowdose triptolide in combination with idarubicin induces apoptosis in AML leukemic stem-like KGla cell line by modulation of the intrinsic and extrinsic factors. Cell Death Dis. 2013; 4:e948.
18. Liu L, Li G, Li Q, Jin Z, Zhang L, Zhou J, Hu X, Zhou T, Chen J, Gao N. Triptolide induces apoptosis in human leukemia cells through caspase-3-mediated ROCK1 activation and MLC phosphorylation. Cell Death Dis. 2013; 4:e941.

19. Mujumdar N, Banerjee S, Chen Z, Sangwan V, Chugh R, Dudeja V, Yamamoto M, Vickers SM, Saluja AK. Triptolide activates unfolded protein response leading to chronic ER stress in pancreatic cancer cells. Am J Physiol Gastrointest Liver Physiol. 2014; 306:G1011-20.

20. Cooley N, Elder RH, Povey AC. The effect of Msh2 knockdown on methylating agent induced toxicity in DNA glycosylase deficient cells. Toxicology. 2010; 268:111-7.

21. Bao S, Wu Q, McLendon RE, Hao Y, Shi Q, Hjelmeland AB, Dewhirst MW, Bigner DD, Rich JN. Glioma stem cells promote radioresistance by preferential activation of the DNA damage response. Nature. 2006; 444:756-760.

22. Dadey DY, Kapoor V, Khudanyan A, Urano F, Kim AH, Thotala D, Hallahan DE. The ATF6 pathway of the ER stress response contributes to enhanced viability in glioblastoma. Oncotarget. 2016; 7:2080-2092. doi: 10.18632/oncotarget.6712. 